Rates of health care-associated Staphylococcus aureus bacteraemia (SAB) and hand hygiene compliance for 21 large metropolitan public hospitals

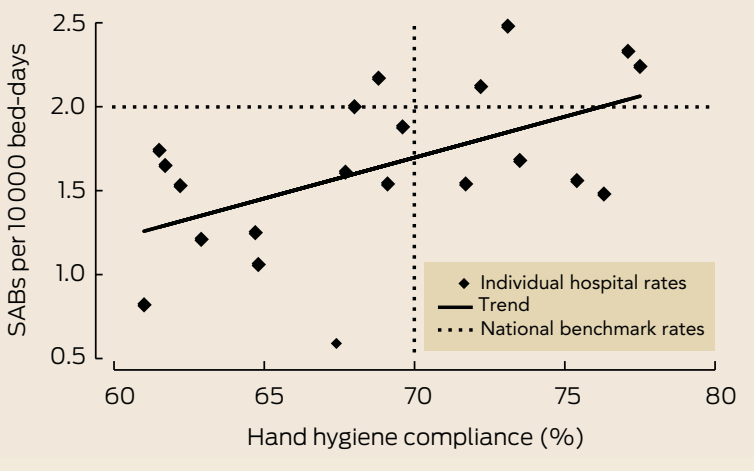

\section{Problematic linkage of publicly disclosed hand hygiene compliance and health care-associated Staphylococcus aureus bacteraemia rates}

TO THE EDITOR: Rates of health care-associated Staphylococcus aureus bacteraemia (HCA-SAB) and hand hygiene $(\mathrm{HH})$ compliance are now subject to public disclosure on the MyHospitals website (http:// www.myhospitals.gov.au). $\mathrm{HH}$ compliance and $\mathrm{HH}$ alcohol hand rub and liquid soap procurement have been associated with reduced methicillin-resistant (but not methicillin-sensitive) S. aureus bacteraemias, generally in the presence of other co-interventions. ${ }^{1,2}$ However, the National Hand Hygiene Initiative advocates that all HCA-SAB (with both methicillin-resistant and methicillin-sensitive organisms) be interpreted as a key indicator of $\mathrm{HH}$ compliance.

We assessed the relationship between $\mathrm{HH}$ compliance (from 1 July to 31 October 2011) and HCA-SAB rates (from 1 July 2010 to 30 June 2011) for 21 large Australian metropolitan public hospitals as currently disclosed (extracted from the MyHospitals website on 13 March 2012).

$\mathrm{HH}$ compliance and HCA-SAB rates were counterintuitively positively correlated ( $r=0.54$; Box), with hospitals with greater $\mathrm{HH}$ compliance showing higher HCA-SAB rates. For every 10 percentage point increase in HH compliance, the HCA$\mathrm{SAB}$ rate increased by 0.5 cases per 10000 bed-days (95\% CI, 0.1-0.9; $P=0.01$ ). Of the five hospitals with HCA-SAB rates above the national benchmark (2.0 cases per 10000 beddays), four also had HH compliance rates above the national benchmark (70\%); of the 16 hospitals with lower HCA-SAB rates, 12 had lower $\mathrm{HH}$ compliance rates.

This counterintuitive relationship highlights the erroneous use of HCA$\mathrm{SAB}$ as an indicator of the impact of $\mathrm{HH}$ compliance, as there are multiple other important causes of HCA-SAB. ${ }^{3}$ In the absence of a reliable indicator, Playford et al HH should instead be evaluated simply by compliance. Even if there was a direct causal relationship 
between $\mathrm{HH}$ and HCA-SAB,

contemporaneous (rather than the presently available non-

contemporaneous) data should be disclosed, particularly where these data encourage judgements about the performance of hospitals.

While $\mathrm{HH}$ is clearly important, it is only one of multiple interventions (including intravascular device management ${ }^{4}$ ) required to reduce HCA-SAB. ${ }^{5}$ This may explain why many hospitals are achieving low $\mathrm{HCA}-\mathrm{SAB}$ rates despite low $\mathrm{HH}$ compliance. It is therefore vital that complex multimodal infection control strategies to prevent HCA$\mathrm{SAB}$ and other infections not be simplistically summarised by $\mathrm{HH}$ compliance alone. With the media scrutiny of hospitals with $\mathrm{HH}$ compliance below the benchmark, it would be unfortunate if hospitals focused only on $\mathrm{HH}$ at the expense of other strategies, simply to achieve the $\mathrm{HH}$ benchmark and avert negative publicity.

E Geoffrey Playford Director and Infectious Diseases Physician

David McDougall Pharmacist ${ }^{1}$

Mary-Louise McLaws Professor ${ }^{2}$

1 Infection Management Services, Princess Alexandra Hospital, Brisbane, QLD.

2 School of Public Health and Community Medicine, University of NSW, Sydney, NSW.

geoffrey_playford@health.qld.gov.au

Competing interests: No relevant disclosures. doi: $10.5694 / \mathrm{mjal} 2.10677$

1 Grayson ML, Russo PL, Cruickshank M, et al. Outcomes from the first 2 years of the Australian National Hand Hygiene Initiative. Med J Aust 2011; 195: 615-619.

2 Stone SP, FullerC, Savage J, et al. Evaluation of the national Cleanyourhands campaign to reduce Staphylococcus aureus bacteraemia and Clostridium difficile infection in hospitals in England and Wales by improving hand hygiene: four year, prospective, ecological, interrupted time series study. BMJ 2012; 344: e3005.

3 Naber CK. Staphylococcus aureus bacteraemia: epidemiology, pathophysiology, and management strategies. Clin Infect Dis 2009; 48 Suppl 4: 231-237.

4 O'Grady NP, Alexander M, Burns LA, et al. Guidelines for the prevention of intravascular catheter-related infections. Atlanta, Ga: Centers for Disease Control and Prevention, 2011. http:// www.cdc.gov/hicpac/BSI/BSI-guidelines2011.html (accessed Jun 2012).

5 Kok J, O'Sullivan MV, Gilbert GL. Feedback to clinicians on preventable factors can reduce hospital onset Staphylococcus aureus bacteraemia rates. J Hospital Infect 2011; 79: 108-114. 